\title{
LEVERAGING DISINHIBITION TO INCREASE STUDENT AUTHORITY IN ASYNCHRONOUS ONLINE DISCUSSION
}

\author{
Dr. Kenneth H. Martin \\ College of Education and Human Development \\ University of Maine
}

\begin{abstract}
Disinhibition is recognized as an effect that prompts online users to communicate with less constraint than in face-to-face discussion. This article describes how disinhibition may affect more than individual instances. In a blended learning environment, disinhibition may alter the entire context of discussion by disrupting established patterns of interaction among students and their teacher. In this developed case study, asynchronous online discussion accompanied classroom instruction in a 12th-grade English class. Online, students interacted with a wider circle of classmates and took more responsibility for managing their discussion while the teacher's presence was more restrained. This study has implications for educators that wish to increase student authority in discussion while supporting their achievement of particular academic and discipline-specific discourse practices.
\end{abstract}

\section{KEY WORDS}

Disinhibition, asynchronous online discussion, threaded discussion, blended learning, hybrid instruction, teaching presence

\section{INTRODUCTION}

This paper addresses the influence of online discussion on interaction patterns among students and their teacher in a secondary school classroom. Online discussion has long been a staple in distance education due to its asynchronous format; that is, participants need not be online at the same time to engage in discussion. Threaded discussion is a form of computer-mediated communication in which participants write and post entries online to a discussion board or forum where these entries are organized into discussion threads. Threaded discussion has the potential to support rich discussion in any educational setting by allowing participants to proceed at their own pace while carefully considering the written record of what others have said. As a distance learning director working with teachers and students in 35 $\mathrm{K}-12$ schools, I became interested in the application of asynchronous online discussion as an alternative to face-to-face discussion in the local classrooms where I worked.

The study reported here was preceded by a study of threaded discussion in a ninth-grade classroom from which two salient themes emerged [1]. First, student informants reported how they felt more comfortable participating online. For example, Beth (all names are pseudonyms), an infrequent contributor in class, reported that with online discussion, "it's different. It gives you courage." The technical term for what Beth described is the online disinhibition effect, meaning that the separation of time and space between participants in an online environment removes certain cautious behaviors that typically constrain face-toface contact [2]. Disinhibition like Beth's is recognized in the literature as assisting "shy" students to participate more and allowing all students to address sensitive issues more freely [3, 4]. Second, informants also reported that their online discussion was less dependent on the teacher's direction when compared with classroom discussion. Evan, for example, noted that "every turn doesn't have to be managed by the teacher." Again, this is an aspect of disinhibition identified as "minimization of status and authority" ([2], p. 324); a tendency by participants in online discussion to ignore or otherwise marginalize 
contributions made by their teacher (see also [5]).

Findings reported here emerged from the case study, which addressed the influence of threaded discussion on literature conversations in a 12th-grade English classroom. Gura and Percy [6] maintain that one challenge to technology integration is to overcome existing norms entrenched within school cultures, including patterns of interaction embedded in conventional classroom discussion. In this case, the separation in time and space inherent in an online environment appears to have encouraged new ways of interacting for both teacher and students. The teacher managed discussion less online than in the classroom, and students interacted online with a wider range of peers than in the classroom. Disinhibition seems to have gone beyond individual occurrences and modified the entire structure of discussion, resulting in increased student authority.

\section{CONCEPTUAL FRAMEWORK}

This study rests on two theoretic frames that share an emphasis on learning as a social enterprise: sociocultural theory and distributed learning environments. According to sociocultural theories of cognitive development, higher psychological functions of memory, thought, and reasoning appear first on the plane of external, social practice before the child internalizes them as mental processes [7]. Learning - including learning to use cultural artifacts like online discussion - involves the child's active mental appropriation of increasingly advanced psychological operations "under adult guidance or in collaboration with more capable peers" ([7], p. 86). For appropriation to occur, learning must be positioned within the learner's zone of proximal development; that is, the adult or more capable peer must provide assistance that builds upon a child's actual development without surpassing what that child is capable of learning with that assistance. What Vygotsky [7] prepares us to appreciate is the potential for assistance to arrive from various others across a distributed environment like today's online discussion.

Second, online environments, generally, are described as distributed $[8,9]$ : neither control nor knowledge is possessed and allocated by single individuals. Instead, both authority and understanding are shared throughout the environment by members engaged in problem solving. Ryder and Wilson [9] state that current technologies "allow for new possibilities. . . Agency is shifting from center to periphery, from teacher to learner [emphasis added], from author to reader, from librarian to researcher, from curriculum to context" (p. 11). Agency is the capacity to make choices and to impose those choices on the world. When this capacity shifts from one central figure to multiple participants, all community members acquire both a right and a duty to influence the community. In other words, distributed environments do more than offer a convenient opportunity to share information; they depend upon the active involvement of all participants in the construction of knowledge.

Consistent with sociocultural learning in distributed environments, the commuity of inquiry (CoI) model [10] represents the way in which participants interact and construct knowledge in online environments. Inquiry-based instruction has a long history in educational studies [11], and various researchers have adopted the inquiry process as a framework for online communication $[8,10,12,13]$. According to the CoI model $[10,12]$, the inquiry cycle occurs in four phases: a triggering event, exploration, integration, and resolution (figure 1). 


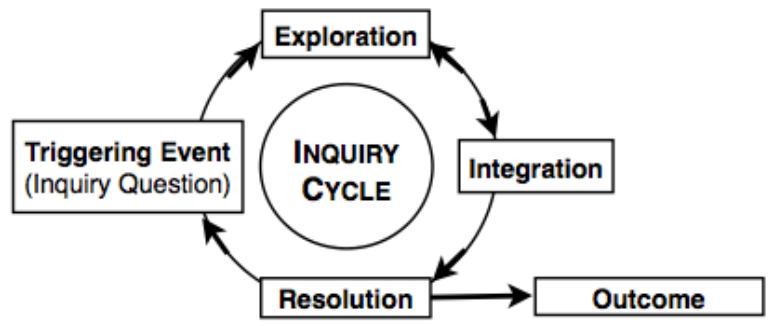

Figure 1. Inquiry cycle representing the four stages of problem solving in a community of inquiry [10].

The first phase in the inquiry cycle is a triggering event or problem that presents an inquiry question. Although the triggering event can originate with any member, in educational settings, it is traditionally initiated by the teacher. The second phase of the inquiry cycle is exploration, in which participants generate and analyze multiple possibilities for answering their inquiry questions. Exploration requires divergent thinking: members clarify the nature of the problem and uncover as much relevant information as possible. The third phase of the inquiry cycle is integration. In this phase, participants begin to synthesize the various possibilities that exploration has generated. Integration requires convergent thinking; members attempt to connect and combine information in order to resolve the inquiry problem. Exploration and integration are not segregated or strictly progressive. Instead, individual participants move back and forth between divergent and convergent thinking. Also, individuals move in and out of group discussion, alternating between their own private reflection and interaction with other group members. In the CoI model, the final phase of inquiry is resolution, in which members arrive at some outcome or response to the original inquiry problem.

Garrison et al. [10] define three conditions that support inquiry in online discussion: social presence, cognitive presence, and teaching presence. Social presence is the capacity of participants in an online environment to represent themselves as "real people" ([10], p. 89); a quality that encourages participation by creating a "warm, open, and trusting environment" ([14], p. 4). Although social presence has been reported as important to participants' satisfaction and to their persistence in completing courses, social presence in and of itself will not guarantee learning outcomes [15, 16]. For inquiry to succeed, participants need to be more than just friendly toward each other; they also need to be committed to purposeful relationships that help the group to think and to achieve learning objectives [15]. This commitment is represented by cognitive presence: a response that develops, evaluates, and extends discussion.

Research indicates that the transition from social presence to cognitive presence can be difficult to achieve. Findings consistently indicate that participants in inquiry-based online discussions tend to remain in the exploration stage rather than move into the latter two stages of integration and resolution $[12,15$, 17]. The inquiry cycle tends to break down between exploration and integration because participants find the latter more demanding, both cognitively and socially [12]. Exploration is a kind of brainstorming that de-emphasizes rules or consequences. Integration, however, requires skills that are more complex mentally and for which students typically feel more insecure emotionally (e.g., probing with questions, pointing out misconceptions, evaluating positions). As Garrison and Arbaugh [15] report, a number of studies point to teaching presence as the critical factor in facilitating the transition from social to cognitive presence in online discussion. Teaching presence encompasses the functions traditionally associated with the position of an instructor; namely, designing and managing the educational experience: developing structures and instructions for discussion; facilitating discourse with model comments and questions; and providing direct instruction by introducing subject matter knowledge and scholarly process leadership [18]. 
Of particular importance to this study is the question of who is responsible for teaching presence. Among those studying this model, there appears to be consensus that teaching presence is the responsibility of the instructor $[15,17,19,20,21]$. However, I would argue that this orientation to the teacher undermines the capacity of online discussion to disrupt conventional patterns of classroom discussion. Consistent with the concept of a distributed environment, the move from a traditional face-to-face classroom into an online environment prompts both students and teachers to redefine their roles and relationship in ways that involve consideration of the teacher's authority [5, 18]. As Gura and Percy [6] suggest, the presence of emerging technologies as a cultural phenomenon will disrupt and to some extent force a change in the habits and practices traditionally embedded in school culture, including discursive practices. Inquiryoriented discussion is most effective when it applies the principles of sociocultural theory to a distributed learning environment in which leadership — what others might call teaching presence — is rightfully shared with students. This study included examination of the extent to which disinhibtion might disrupt established relationships among discussion participants, including the teacher, and thereby support students' learning and increasing responsibility for functions traditionally reserved to their teacher.

\section{METHODOLOGY}

This case study documented the influence of Moodle Forum, a specific application of threaded discussion. The setting was a regional high school serving a rural district of five towns with a combined population of 5,500. Riverside High School was a regional 9th-12th grade public high school. In the 2010-2011 school year, enrollment was 225 students with a male/female ratio of $48 \%$ to $52 \%$, including $92+\%$ Caucasian, 7\% Hispanic, and less than 1\% African American or Asian students. In the Riverside School District, the median income was $\$ 28,525$ with $56 \%$ of students eligible for free and reduced lunch. Total faculty and staff numbered 39 and average class size ranged between 12 and 18; 3.8\% of students received special education services [22].

Riverside High School was the site of my earlier study [1] and was chosen for two reasons. First, Riverside encouraged technology use, and its faculty and staff were committed to technology integration. Second, Ms. Hawthorne, the classroom teacher featured in this study, had a record of leadership in the school's efforts to integrate technology.

Every student at Riverside High School had a dedicated MacBook laptop computer for use throughout the school day and at home. Although the school's technology program did not address Internet access outside of school, teachers, including Ms. Hawthorne, had found that most students did have regular access to the Internet outside of school, and where necessary, accommodations were made to provide access in school while out of class. The opportunity and expectation that discussion would be conducted outside of class preserved the orientation of this study toward asynchronous online discussion.

I was positioned as a participant-observer. The classroom teacher, Ms. Hawthorne, identified me as a technology integration coach assisting her and her students in the use of Moodle Forum. Introducing myself as a researcher conducting a study of students' use of online discussion, I provided direct instruction in the use of Moodle Forum, as well as coaching in practices related to online discussion.

\section{A. Participants}

Participants in this study were from two class sections of 12th-grade English. These were general English sections comprised of students that had chosen not to take the Advanced Placement Senior English course, and the majority had been identified by their teacher as underperforming, particularly with respect to homework completion. From a total of 34 students in these two sections, parental consent to participate was obtained for 20 students who became participants in this study. Of the 20 participants, 14 were female and 6 were male. Nearly half had prior experience with Moodle Forum, but only four had participated as ninth graders in the earlier study. Fifteen of the twenty participants had Internet access outside school while five did not. All participants were familiar with using e-mail, surfing the Internet, and utilizing social networking. All but two had cell phones. Altogether, each participant was a frequent user of technology involving online communication. 
Upon analysis of initial observational and survey data, I selected a smaller subset as primary informants. This subset was comprised of three participants (two male and one female) from the period 2 class and four participants (two male and two female) from period 6. These seven students provided a representative sample of academic performance, work habits (including frequency of assignment completion), and class participation as characterized by their teacher and my own classroom observation during the first three weeks of the study. Of the seven primary informants, three had been primary informants in the earlier study - Beth and Evan in period 2 and Valerie in period 6. It is also important to note that two participants in period 6 (Norman and Matt) had already read the principal text for this study, The Great Gatsby, as members of Ms. Hawthorne's Junior Advanced Placement English class.

\section{B. Data Collection and Analysis}

Data collection began in September 2010 and ended in December 2010, approximately the duration of the students' first semester of 12th-grade English. During this time, I was in the classroom three days each week, including one 80-minute block period and two 50-minute periods for each class. Data collection included observational field notes, student surveys, interviews with the seven primary informants and their classroom teacher, and of primary importance, complete transcripts of forum discussions, including entries from all students in the class. The unit of analysis was the particular rhetorical features evident in entries that participants produced on Moodle Forum. In my capacity of assisting the class to adopt Moodle Forum, I had access to Forum transcripts including entries from all students in the class. Of course, it was necessary for me to disaggregate the entries of the 14 non-participating students and to attend only to entries made by the 20 participating students. It is accurate to note that the removal of entries by non-participating students complicated the analysis of less than 5\% of entries posted by participating students.

Throughout the data collection period, discussion forum transcripts were printed and analyzed each week. A system of tentative master and sub-codes was derived from the study's main and secondary questions to identify targeted sociolinguistic features in the Moodle Forum transcripts [23]. During initial coding runs, sociolinguistic deductive codes were revised as required, and additional emerging master and sub-codes were developed using an inductive approach [24]. Near the conclusion of data collection when a stable set of sociolinguistic master and sub-codes was in place, I tested the external reliability of my code definitions by conducting an inter-reader reliability session with research colleagues who were not familiar with my data. I achieved $78 \%$ agreement in the application of codes to the transcript of a threaded discussion containing 22 entries. Inter-reader reliability was achieved in this first session, and I began sociolinguistic analysis of all discussion forum transcripts.

Primary informants were interviewed three times, using a semi-structured protocol: once upon selection during week 4, a second time at the end of the instructional phase (week 6), and a third time at the end of data collection (following week 14). Midway through the data collection period, I began to apply a separate "start list" of codes [23] to secondary data, beginning with the first interview with primary informants. Deductive codes were revised as required, and additional emerging master and sub-codes were developed using an inductive approach [24]. Near the conclusion of my study when a stable set of master and sub-codes was in place, I generated a coding dictionary and coding map and began analysis of secondary sources of evidence: observational field notes, research journal entries, analytic memos, and interview transcripts. Inter-reader reliability for codes applied to secondary sources of evidence was deemed non-essential for two reasons. These sources were subordinate in importance to the discussion transcripts, and codes devised and tested for the secondary sources of evidence were similar in nature to those devised and applied to transcript data. Once descriptive coding of the data set was complete, I converted salient master and/or sub-codes into pattern codes or themes [23].

\section{Limitations of the Study}

This study was a qualitative case study in which analysis of the data set was supplemented by limited quantitative analysis. Assessing the frequency of sub-codes and sociolinguistic features represented 
quantification essential to data reduction but was not a suggestion of a quantitative methodology. No claim is made as to a generalized use of the results of this study. With 20 participants and 7 primary informants, the sample size is appropriate to ethnographic studies that necessarily involve smaller participant samples, yet the degree of particularity represented in results reported here naturally leaves readers to judge any applicability to their own circumstances [25]. The participant sample was also limited to students from whom parental consent was obtained to participate (20 of 34 total students). While it is possible to speculate that the 14 non-participating students represented a particular subset of the classes (e.g., students with less home support or interest in school), it is not possible to know whether or how these 14 may have affected the findings in this study. Moreover, it is fair to note that the 20 participating students did represent the gender, socio-economic, and academic characteristics of these class sections as a whole.

Participant-observer research generally involves the inherent risk of perception prejudiced in favor of a particular outcome [26]. This risk to data analysis and reporting in this case study was intensified in two ways. First, the researcher's general stance as an advocate for technology integration might generate the impulse to promote the benefits of Moodle Forum. Second and more critically, the researcher had been a teaching colleague of the classroom teacher for three years and had coached Ms. Hawthorne on the use of technology for two years. Moreover, some of Ms. Hawthorne's senior students had participated as ninth graders in the prior study on Moodle participation [1]. These prior associations could reasonably be expected to have increased the researcher's inclination to gloss actions or expressions that might reflect poorly on either the teacher or students.

Trustworthiness in light of the above concerns was addressed in multiple ways. Most importantly, the unit of analysis, discussion entries, was dependent on Moodle Forum transcripts for which coding reliability was tested with readers unfamiliar with the data. Verbatim transcripts of every online discussion during the research study made incontrovertible certain data collected (e.g., numbers of entries posted or replies made to other participants) and provided an unabridged record of sociolinguistic features in evidence. Analysis of discussion and interview transcripts was designed to determine whether the perceptions about Moodle Forum that informants expressed correlated with their actual discourse activity. Following the completion of data collection, member checks were conducted with each informant to confirm the accuracy and persistence of statements made. Triangulation of this data along with classroom observation and teacher interviews assisted the interpretation of online discussion activity within the specific context of this case study. In this way, the data set was analyzed and compared to ensure that the different sources of data were answering the intended research questions and yielding similar results. As suggested by Miles and Huberman [23], this provided for triangulation both by data source and by method (p. 267).

\section{Moodle Forum: The Instructional Intervention}

Instruction in the use of threaded discussion was embedded in an inquiry unit around the question, "How is character shaped?" This 15-week unit was divided into two phases. A 5-week, instructional phase utilized short texts (e.g., music, images, poetry, short stories) to introduce the inquiry unit and Moodle Forum. In accordance with a gradual release of responsibility model for instruction [27], phase 1 began with my introduction of the Moodle Forum technology and Ms. Hawthorne's initiation of rhetorical strategies followed by modeling, coaching, and student practice. The culminating event in phase 1 was a discussion of the short story, "Thank You, M'am" [28]. In this story, an apparently poor, working woman catches a boy who attempts to steal her pocketbook, and in a sense, she rewards him by taking him home for supper and giving him a $\$ 10$ bill before releasing him. The second phase lasted 10 weeks and used The Great Gatsby by Fitzgerald [29] to further instruction and student practice. Throughout this inquiry unit, the classroom teacher and I explained and modeled each design element, and Ms. Hawthorne guided students in practicing to use the elements in a series of whole class and small group activity structures. 


\section{RESULTS}

This case study did involve examples of the primary disinhibiton effect; that is, a tendency in online contexts for shy students to participate more and all students to participate more freely on sensitive subjects [3, 4]. One example was discussion of the incident in The Great Gatsby when Tom Buchanan breaks his mistress Myrtle's nose. During in-class discussion, students in each section uniformly took the position that Tom was somehow justified in this response to Myrtle taunting him about Daisy. In the subsequent Moodle Forum, however, Laney and Michelle in period 2 took the opposing position that no action on Myrtle's part could justify Tom's physical abuse. What is significant in this case study, however, are the two ways in which the disinhibited actions of participating students and their teacher affected customary patterns of interaction, thereby restructuring their discussions altogether. First, students expanded the circle of classmates with whom they communicated. Second, the teacher participated infrequently online, and students stepped forward to take on responsibilities that were customarily left to her in class discussion. The following results will indicate that Moodle Forum was a distributed environment where (a) participation was based less on pre-existing social structures and more on constructing knowledge through entries posted, (b) agency for managing discussion shifted from the teacher to students, and (c) student authority increased as more capable students provided teaching presence to assist classmates in advancing the quality of their work.

\section{A. Student-to-student: Toppling the Established Social Order}

There is evidence that when students went online, they altered the patterns of interaction to which they were accustomed in the classroom. In biographical surveys prior to data collection, participants identified a circle of friends - three to five other students in the class that they would "most likely choose to work with on a project." Classroom observation subsequently confirmed that participants sat with these friends almost exclusively and chose to join in activities with the circle they had identified. Online, however, participants in both periods responded more or less equally to those outside as well as inside their friendship circle. Moreover, response to those outside their customary circle increased as the study progressed (table 1).

Table 1. Percentage of Moodle Forum replies participants made to classmates within and outside their circle of friends.

\begin{tabular}{|l|c|c|c|c|}
\hline & \multicolumn{2}{|c|}{ Period 2 } & \multicolumn{2}{c|}{ Period 6 } \\
\hline & Within Circle & Outside Circle & Within Circle & Outside Circle \\
\hline Phase 1 & $61 \%$ & $39 \%$ & $50 \%$ & $50 \%$ \\
\hline Phase 2 & $43 \%$ & $57 \%$ & $30 \%$ & $70 \%$ \\
\hline
\end{tabular}

This dispersed interaction appears not to have been overlooked by participants. When asked to whom they had responded most on the forum, four of the seven primary informants identified not only members of their cluster, but also students outside their circle of friends. What these primary informants suggested is that their own disinhibition related not just to what students wrote about, but also to the selection of those to whom they wrote. Regardless of the topic, participants seemed to have been less constrained in their selection of partners on Moodle Forum than they were in the live classroom.

Beth in particular spoke in detail about how the circle of discussion was different online from offline. While Beth described herself as a "social butterfly" that could talk with anyone, she characterized high school in general as an entrenched social hierarchy, and she explained the risks inherent in going outside one's own group. For most students, talking with someone from a group considered lower in the social hierarchy would result in ridicule, and disagreeing with someone outside the relative safety of school could lead to being beaten up. Responding to others on Moodle, she felt these consequences did not exist: 
I've noticed a lot of people that are higher up on the social list-let's just say that. They talk to people that they normally wouldn't talk to. And that's saying a lot. It doesn't mean that they don't want to talk to them when they're outside Moodle. It just means that they feel safer talking to them through Moodle because they can't get made fun of. They can't get laughed at for talking to that certain person or replying to that certain person. They kind of take it as a safe haven.

As a primary informant in the earlier study during her ninth-grade year, Beth had spoken directly to the separation of time and space in online environments as giving her the "courage" to speak up and contribute to online discussion. Here, three years later, she distinguished disinhibition as giving cover to anyone who might not be comfortable risking interaction with those outside their group in a face-to-face setting. As she explained it, Moodle Forum discussions would not change relations outside of Moodle, but they would provide one setting for secure interaction outside students' regular fixed groups.

What Beth's description suggests is more than a change in individual forum posts. It implies that disinhibition engendered an entirely different environment for interaction from the classroom setting to which these students were accustomed. Face-to-face interaction in the classroom was bound by a social hierarchy with customs and rules external to the roles and objectives of their English class. Online, however, students' out-of-class and out-of-school associations appear to have receded in favor of a new web of relationships based on the capacity of participants to contribute to the group's construction of meaning.

\section{B. Teacher-to-student: Dismantling the Accepted Power Structure}

Patterns of discourse involving the classroom teacher also appear to have been altered online. Ms. Hawthorne's number of Moodle Forum entries over the duration of this study was limited. In phase 1, Ms. Hawthorne posted a total of five entries to the four instructional discussions. In phase 2, she posted a total of three entries to the five Gatsby forums. Primary informants seem to have recognized her limited presence but did not seem to have been troubled by it. When asked to "describe Ms. Hawthorne's participation in Forum discussions," two of the seven primary informants explicitly reported that "she really didn't participate that much," and five reported that they could not remember her participating. However, no primary informant expressed being upset, disappointed, or otherwise critical of Ms. Hawthorne's participation.

For her part, Ms. Hawthorne reported a pedagogical basis for limiting her participation: she hoped to reduce her influence, believing that less teacher presence might encourage students to take more responsibility for the discussion. She hoped that students themselves would manage the course of discussion rather than rely on her, as they often seemed to do in the live context of the classroom. In the post-study interview, Ms. Hawthorne described her position this way:

My original thought in refraining from participation in the Forums was to provide students with a place where they could learn to carry on real academic discussion of their own. I thought if I was too present, the discussion couldn't be anything but "teacher-centered"-that students would see the discussions as just another "hoop" to jump through.

For Ms. Hawthorne, a central objective in learning to discuss literature was for students to take not only an interest in participating, but also to gain a sense of responsibility for conducting the discussion. This was a marked departure from her role in classroom discussion. In her second interview, Valerie observed, "Ms. Hawthorne's funny because some people don't read the book like they should, and Ms. Hawthorne just tells them everything that had happened. I mean, she doesn't want them to do bad, so that helps them in a way." What Valerie described is in-class discussion in which the instructor is central to the management and content of discussion. Forum analysis revealed that Ms. Hawthorne did not feel the same compulsion to rescue students in online discussion.

Suler [2] identifies "minimization of status and authority" as one aspect of online disinhibition (p. 324). People may fear the disapproval of an authority figure in a face-to-face encounter. "But online, in what feels more like a peer relationship ... people are much more willing to speak out and misbehave" ( $p$. 
324). Similarly, Anagnostopoulos et al. [5] identify this minimization of authority as de-centering, a tendency by participants in online discussion to ignore or otherwise marginalize contributions made by their teacher. In a sense, Ms. Hawthorne was hoping to leverage this effect by withdrawing from online discussion preemptively. Consistent with sociocultural learning theory, she recognized it would not be enough for students to alter their own patterns of interaction and communicate with a wider circle of contacts if their teacher remained as a dominant, central authority. In order for them to achieve a rich plane of social learning, it would also be necessary for her to withdraw, thereby making her authority open to distribution as well. Disinhibition appears to have afforded her the cover needed to retreat, and she hoped that her absence would motivate students to step forward and lead.

\section{Evidence of Teaching Presence by Students}

Given Ms. Hawthorne's decision to limit her own participation as well as her students' apparent acceptance of her stance, what evidence was there that participants took up the responsibility their teacher afforded them? As noted, teaching presence is considered central to online discussion as a way to influence discussion directly and indirectly. It is also considered essential to advancing the inquiry process by supporting the move from social to cognitive presence: in this case, there was evidence of student participants' taking on teaching presence. Two examples provide this evidence. The first has to do with originating the agree-and-disagree reply protocol. In the use of any technology, protocols are the social or cultural practices that embody the expectations and relationships of the technology's users [30]. Protocols may be devised or required by authority (e.g., the teacher), or participants may negotiate protocols, formally or informally, in the context of use. The extent to which students negotiated protocols rather than relied on their teacher to provide them may indicate the degree to which their environment was distributed and their tendency toward social learning.

The agree-and-disagree reply structure was a protocol that students themselves developed for composing discussion entries. During a class discussion in period 6 about composing replies to other forum posts, Ellen stated that she liked to start an entry "by saying something nice to the other person." In response, I introduced the concept of social presence and explained that even though a reaction like "Great entry" needed more to extend the conversation, openers like this were instrumental in encouraging everyone to participate in the discussion. Ellen then asked if it was "alright to disagree with people" in discussions. This question proved to be a pivotal one as other students expressed that they often wanted to disagree with a post but did not know how to do so without hurting others' feelings. In response to Ellen's question, Ms. Hawthorne conducted a mini-lesson in each class, introducing sentence stems for initiating disagreement. Subsequent to this discussion and without further instruction from their teacher or me, students themselves introduced a strategy of beginning entries with a statement of agreement before introducing a point of disagreement (figure 2).

\section{L3 - (9) Re: Respect \\ BY LANEY - Monday 09:37 AM}

...It's just like when a child does something bad. The parent can either spank them, or sit them down and explain to them what they did wrong and why they are going into time out...

$$
\begin{aligned}
& \text { L4 - (10) Re: Respect } \\
& \text { BY CARLTON - Monday 09:40 AM }
\end{aligned}
$$

But the problem is what if the kid won't listen to the parents?

Then what are you suppose to do to them?

You can't really try to explain again because they will just ignore you

L5 - (11) Re: Listening

BY LANEY - Monday 09:44 AM 
Yes, there is some truth to that. But if the kid has respect he will automatically listen to the parents. I mean there is some punishment with the talk as well. There are the options of timeout, taking away a toy...

Figure 2. Agree-and-disagree reply protocol (shaded) from Forum discussion of "Thank You, Ma'm" in period 2.

Forum analysis as well as informant reporting established the importance of disagreement to engaging online discussion. Six of the seven primary informants identified the potential to disagree with individual Moodle Forum entries as the single most compelling factor in creating a response. Four of the seven primary informants claimed that the potential for disagreement diminished in the Gatsby forums, and transcript analysis seemed to confirm this trend. In the discussions around "Thank You, M'am" at the end of phase 1, more than $40 \%$ of the forum replies expressed some degree of disagreement. In subsequent Gatsby forums, reply entries expressing disagreement dropped below 15\%. Coincidentally, the total number of forum entries declined by almost half from one phase to the next. Matt in period 6 explained the situation this way:

It was just hard with this book because we all had the same basic idea about it. I mean, it wasn't "Thank You, M'am" where there were two distinct thoughts going in line. . . . With Gatsby, it was one prominent feature, everyone hates Daisy. . . It was always the same, just do you agree or what do you think? If there was more controversy, you would've gotten more heated discussion. And then, you want to get back to it, even with no credit or anything, you just want to put your thought down.

Matt clearly identified contention as a key feature of online discussion. He attributed quality discussion of "Thank You, M'am" to students advancing opposing positions, and he criticized discussion of The Great Gatsby as monotonous, mired in a single topic on which everyone took the same stance. In a larger sense, Matt claimed that the opportunity for disagreement provides intrinsic motivation toward learning itself: "You want to get back to it, even with no credit or anything." In this way, Matt recognized discussion as an inquiry process in which controversy was essential to sustained investigation of a topic. Accordingly, the ability of participants to express disagreement would be essential to achieving both sustained discussion and the cognitive presence required for inquiry.

Although Ms. Hawthorne provided the sentence stems for expressing disagreement, students independently developed the strategy of beginning entries with a statement of agreement before introducing a point of disagreement. In the agree-and-disagree pattern, participants appear to have devised a protocol for composing entries that assisted them to simultaneously disagree and maintain a trusting social environment. From an inquiry perspective, participants took the initiative to fashion their own protocol that assisted them to preserve social presence by acknowledging agreement while moving toward cognitive presence by expressing disagreement. In other words, they devised a protocol for teaching presence.

A second example of teaching presence involved direct instruction, specifically efforts at scholarly leadership by Matt and Norman to direct discussion in ways associated with academic inquiry. One concept central to Ms. Hawthorne's reading pedagogy was authorial intent: the idea that skilled authors like Fitzgerald do nothing by chance or without thought. Instead, every narrative move or detail of character is purposeful. In support of this concept, Ms. Hawthorne demanded textual reference in classroom literature discussions. Rather than merely following their teacher's explicit instruction in referencing texts (as a majority of participants did), Matt and Norman instructed classmates in online discussion to observe her requirement and instruction as well. For example, following a student's post that asked, "Is it just a coincidence [that Gatsby would live across the bay from Daisy]?" Matt responded, "I'm going to start this off by saying something Ms. Hawthorne has been saying for a while . . . 'Fitzgerald did not just throw this book together the night before it was due. He writes with intent!'" In Matt's view, the initial question was essentially invalid: we may disagree on what Fitzgerald's intent was, but we cannot disagree that as an author, he had intent of some kind. In this way, Matt attempts to direct discussion toward a particular concern of literary analysis, one indicator of teaching presence [18]. 
In coaching classmates on authorial intent, Matt explicitly invoked the identity of his teacher to accredit his instruction. Elsewhere, Norman took direct instruction a step further. In a discussion of why Gatsby might keep such a low profile, avoiding most guests at his own lavish parties, Norman did not speculate on Gatsby's motivation. Instead, he explained why he believed the author, Fitzgerald, might have positioned Gatsby in this way.

I think that the author chooses [emphasis added] not to talk too much about Gatsby at first because if you think about it we really don't need to know that much about him. We need to know about Nick and where he comes from. If we didn't know about Nick and Tom, I think we would be confused. The author made it like this for a purpose [emphasis added].

In this entry, Norman did not cite Ms. Hawthorne directly, let alone quote her as Matt did. Nevertheless, Norman's attention to authorial intent is unmistakable in his use of the phrases "the author chooses" and "the author made [the text] like this for a purpose." In taking this stance, Norman took responsibility for the concept of authorial intent without relying on the authority of his teacher. This move represents both increasing ownership of the concept and teaching presence to direct others toward literary analysis.

It is true that both Norman and Matt were best prepared to provide teaching presence by virtue of their prior study of The Great Gatsby in Ms. Hawthorne's Junior Advanced Placement class. To enact teaching presence requires more than interest and self-confidence. As Ms. Hawthorne noted in her post-study interview, "It's not enough simply to say, 'Oh, I want to be a teacher."' It is also about the extent to which the context of learning positions students to be teachers. Nevertheless, it seems equally true that the opportunity to take on this role was enhanced by the online disinhibition effect upon the teacher as well as participating students. Faced with Ms. Hawthorne's absence from online discussion, Matt and Norman stepped in to supply the teaching presence that all were accustomed to in the face-to-face classroom.

\section{IMPLICATIONS}

Findings in this study revealed that participants interacted differently during online discussion than in face-to-face discussion. Going online seemed to disrupt established discourse patterns among these 12thgrade students and their teacher. Students communicated with a wider circle of contacts; the teacher participated infrequently, thereby relinquishing management of the discussion; and certain students stepped forward to assume that teaching role. These findings provide a basis for two assertions, each of which calls for further research to determine its validity beyond the present case:

1. Going online provided a distributed environment in which a new, more egalitarian web of relationships replaced (to a degree) the hierarchical social structure characteristic of the classroom, and this change oriented participants more toward content and less toward social relations - toward what was posted rather than who was posting.

2. By withdrawing from discussion and leaving the online space to her students, Ms. Hawthorne further leveled the discussion space; consequently, students, especially Norman and Matt, recognized and accepted her invitation to enter in and lead as they were ready and able to do so.

Together, these assertions depict a progression toward increased student authority that may flow from the disinhibition effect of moving to an online environment. These assertions also invite further research on multiple questions.

Certain questions flow from the limitations of this qualitative study. The sample size was relatively small and included only students for whom parental consent had been obtained. Any characteristic common to students that did not participate (e.g., lesser parental support for their schooling) may have affected results. Additional questions are embedded in the context of this study's instruction. Would the results reported from this English class also occur in math and science classes? Indeed, what might the effect be in any discipline where content is not just different but also considered more central than language process concerns (such as conducting discussions)? Would similar results occur in a school without a 1 to 1 laptop-to-student ratio? In this study, students appear to have capitalized on the disinhibition effect even when they were working online in each other's physical presence. Nevertheless, the relative importance to 
different students of a separation in space as well as time merits further study.

Particularly important questions relate to teachers' applications of the assertions made here. The first question is whether students will routinely expand their circle of contact when communicating online in a blended environment. Classrooms in this study provided just two examples of this effect. However, even though this study was not very large, online discussion may be a route worth further exploration by teachers who want students to talk with a wider circle of classmates than in typical face-to-face contact. Additionally, further study of Moodle Forum discussion entries is needed to assess the impact on content when a wider circle of peers are involved. If students are indeed less oriented toward social influences online, how does that affect the substance of their entries? On a related note, is there any reciprocal impact on subsequent discussion in the face-to-face environment? Although one informant (Beth) claimed that the Moodle Forum experience would not alter established social patterns in the regular school environment, it is difficult to imagine that classroom discussion would become less egalitarian as a result of online discussion. Nevertheless, this question was beyond the scope of this investigation.

A critical question raised by this study involves assertions about realizing teaching presence: What is the efficacy of restraining the teacher's presence? If teachers refrain from online discussion, what is the likelihood that students will readily and effectively assume teaching responsibilities? Other researchers contend that the teacher's presence is essential during online discussion in order to provide knowledge and scholarly leadership that students cannot provide $[15,17,18,19,20,21]$. Without discounting that position, this study argues that the importance of a teacher's influence does not preclude students' learning to be responsible for functions traditionally reserved to their teacher. As in this case, agency can shift from teacher to student in an online context. This is not to suggest that teaching presence will arise simply by moving literature discussions online. To the contrary, in each instance cited here, the teacher was instrumental to students' enactment of teaching presence. Protocols for the use of Moodle Forum were developed in the classroom and practiced online (e.g., the agree-and-disagree response pattern); rhetorical protocols that were emphasized in the classroom were evident in discussion forums (e.g., textual references were given to substantiate authorial intent). The live classroom was instrumental to developing and acquiring these strategies, while the Moodle Forum seemed to have been conducive to their practice. What this process suggests is a cycle of instruction made possible by the interdependence of offline and online spaces in a blended environment. Effective online discussion begins in the classroom where the teacher's explicit instruction and modeling as well as the negotiation of discourse protocols introduce students to rhetorical strategies. Students then develop their rhetorical skills online where practice is supported by the individualized pace and written nature of online discussion coupled with the disinhibition effect of working online. Finally, in a return to the classroom for debriefing, the teacher provides responsive intervention to assist students in examining the record of their discussion before returning again to the online space.

Students' online discussions were not regularly or fully debriefed offline in this study. Therefore, further research is needed with respect to cycling instruction between these two spaces. Nevertheless, to the extent teachers seek to limit their online contributions, they may well find that active intervention in the offline stages of this cycle assists students' online discourse. This realization is important to blended environments where the asynchronous nature of online discussion allows practitioners to move discussion outside the classroom, especially since it can be tempting to regain valuable class time by relocating discussion entirely online. This case indicates that secondary students may be more apt to benefit from coordinating online discussion with related activity in class. This position does not suggest that threaded discussion should never be used independently outside the classroom, but it does recommend technology integration that blends online and offline spaces in mutually supportive ways. In this way, the two guiding forces envisioned by Vygotsky [7] can most effectively be leveraged. In the classroom, the teacher and students with leadership skills can assist every student's progress through individual zones of proximal development. Online, students may assist their peers' development by exhibiting teaching presence while advancing their own learning through this action. Students need to be prepared for teaching presence or 
they won't be able to take it on. At the same time, students need to be charged with teaching presence or they may not be motivated to establish it.

A final question raised by this study is whether results would be similar in a totally online class. It is difficult even to speculate on how the social circles would be affected since this study relates to prior, established relationships among the participants. Presumably, the disinhibition effect in an online class would be similar for those with any face-to-face connection outside the online space, but there is no context for comparison on this point in strictly online environments.

With respect to teaching presence, the effect of the teacher's restrained participation may be less a matter of whether teachers do or do not participate and more a question of degree: when, how often, and in what manner they enter a discussion. In one respect, findings here should allay teacher concerns about replying equally to all students from an arbitrary sense of fairness rather than responding authentically as process needs arise or their own interests suggest. Perhaps teachers can approximate the cycle of instruction suggested above by somehow distinguishing instruction and practice in a totally online environment. While teachers may need to provide direct instruction in discussion protocols and strategies, providing some discussion space that students manage independently seems equally important. How these spaces are identified and balanced in totally online environments merits further study.

\section{CONCLUSION}

Definitions of social presence generally emphasize how participants represent themselves - the way in which individuals project their personas or position themselves to be perceived by others within the online environment $[10,14]$. Users select and introduce characteristics of their personality depending on their situation, and "different modalities of online communication ... and different environments ... may facilitate different expressions of self" ([2], p. 325). The disinhibition effect has been recognized for affecting individual participation in online discussion. What is significant and unique in this study is evidence that the disinhibition effect may be more complex than the choices individuals make about their own self-representation. Here, going online seems to have altered the context of discussion itself as represented in the discourse patterns of its participants. Investigation of online discussion includes two persistent questions related to student agency: can students take up teaching presence, and in doing so, can they make the transition from exploration toward resolution, thereby advancing the inquiry cycle? This study invites further investigation of how a broader understanding of the disinhibition effect may foster increased student authority toward these ends in asynchronous online discussion.

\section{REFERENCES}

1. Martin, K. H. Moodle Forums in Ninth-Grade English: Engaging Students with Threaded Discussion. Unpublished manuscript, 2008.

2. Suler, J. The Online Disinhibition Effect. CyberPsychology \& Behavior 7(3): 321-326 (June 2004). http://www-usr.rider.edu/ suler/psycyber/disinhibit.html.

3. Asterhan, C. S. C., and Eisenmann, T. Introducing Synchronous E-discussion Tools in Co-located Classrooms: A Study on the Experiences of "Active" and "Silent" Secondary School Students.

Computers in Human Behavior 27(6): 2169-2177 (November 2011). doi:10.1016/j.chb.2011.06.011.

4. Kirk, J. J., and Orr, R. L. A Primer on the Effective Use of Threaded Discussion Forums. ERIC database (January 2003).

http://www.eric.ed.gov/ERICWebPortal/contentdelivery/servlet/ERICServlet?accno=ED472738.

5. Anagnostopoulos, D., Basmadjian, K. G., and Mccrory, R. S. The Decentered Teacher and the Construction of Social Space in the Virtual Classroom. Teachers College Record 107(8): 1699-1729 (August 2005).

6. Gura, M., and Percy, B. Recapturing Technology for Education: Keeping Tomorrow in Today's Classroom, Lanham, MD: Scarecrow Education, 2005.

7. Vygotsky, L. S. Mind in Society: The Development of Higher Psychological Processes. Cambridge, MA: Harvard University Press, 1978. 
Leveraging Disinhibition to Increase Student Authority

in Asynchronous Online Discussion

8. Duffy, T. M., Dueber, B., and Hawley, C. L. Critical Thinking in a Distributed Environment: A Pedagogical Base for the Design of Conferencing Systems. In: C. J. Bonk \& K. S. King (Eds.), Electronic Collaborators: Learner-Centered Technologies for Literacy, Apprenticeship, and Discourse, Mahwah, NJ: Lawrence Erlbaum Associates, 51-78, 1998.

9. Ryder, M., and Wilson, B. Affordances and Constraints of the Internet for Learning and Instruction. Paper presented at the National Convention of the Association for Educational Communications and Technology, Indianapolis, IN (February 1996).

http://eric.ed.gov/ERICWebPortal/contentdelivery/servlet/ERICServlet?accno=ED397833.

10. Garrison, D. R., Anderson T., and Archer, W. Critical Inquiry in a Text-based Environment: Computer Conferencing in Higher Education. The Internet and Higher Education 2(2-3): 87-105 (Spring 1999). doi:10.1016/S1096-7516(00)00016-6.

11. Dewey, J. How We Think, Mineola, NY: Dover Publications, 1997.

12. Garrison, D. R., Anderson T., and Archer, W. Critical Thinking, Cognitive Presence, and Computer Conferencing in Distance Education. American Journal of Distance Education (AJDE) 15(1): 7-23 (2001). http://communitiesofinquiry.com/cognitive_presence.

13. Gunawardena, C. N., Ortegano-Layne, L., Carabajal, K., Frechette, C., Linderman, K., and Jennings, B. New Model, New Strategies: Instructional Design for Building Online Wisdom Communities. Distance Education 27(2): 217-232 (August 2006).

14. Rourke, L., Anderson, T., Garrison, D. R., and Archer, W. Assessing Social Presence in Asynchronous Text-based Computer Conferencing. The Journal of Distance Education 14(2): 50-71 (1999). http://www.jofde.ca/index.php/jde/article/view/153/341.

15. Garrison, D. R., and Arbaugh, J. B. Researching the Community of Inquiry Framework: Review, Issues, and Future Directions. The Internet and Higher Education 10(3): 157-172 (April 2007). doi:10.1016/j.iheduc.2007.04.001.

16. Picciano, A. G. Beyond Student Perceptions: Issues of Interaction, Presence, and Performance in an Online Course. Journal of Asynchronous Learning Networks (JALN) 6(1): 21-40 (July 2002). http://citeseerx.ist.psu.edu/viewdoc/download?doi=10.1.1.98.6506\&rep=rep1\&type=pdf.

17. Swan, K. Threaded Discussion. Paper presented at the Ohio Digital Commons for Education (ODCE) Conference: The Convergence of Libraries, Learning, and Technology, Columbus, $\mathrm{OH}$ (March 2006). http://www.oln.org/conferences/ODCE2006/papers/Swan_Threaded_Discussion.pdf.

18. Anderson T., Rourke, L., Garrison, D. R., and Archer, W. Assessing Teaching Presence in a Computer Conferencing Environment. Journal of Asynchronous Learning Networks (JALN) 5(2): 117 (September 2001). http://communitiesofinquiry.com/teachingpresence.

19. Garrison, D. R. Online Collaboration Principles. Journal of Asynchronous Learning Networks $(J A L N)$ 10(1): 25-34 (February 2006). doi:10.1.1.96.4536\&rep=rep1\&type=pdf.

20. Shea, P. J. A Study of Students' Sense of Learning Community in Online Learning Environments. Journal of Asynchronous Learning Networks (JALN) 10(1): 35-44 (February 2006). http://www.sloan-c.org/publications/jaln/v10n1/pdf/v10n1_4shea.pdf.

21. Swan, K. P., Richardson, J. C., Ice, P., Garrison, D. R., Cleveland-Innes, M., and Arbaugh, J. B. Validating a Measurement Tool of Presence in Online Communities of Inquiry. e-Mentor 2(24) (2008). http://www.e-mentor.edu.pl/artykul/index/numer/24/id/543.

22. Riverside High School. Riverside High School Accreditation Report, Riverside, ME: Riverside School District (2010).

23. Miles, M. B., and Huberman, A. M. Qualitative Data Analysis: An Expanded Sourcebook, Thousand Oaks, CA: Sage Publications, 1994.

24. Strauss, A., and Corbin, J. Basics of Qualitative Research, Newbury Park, CA: Sage, 1990.

25. Merriam, S. Qualitative Research in Practice: Examples for Discussion and Analysis, San Francisco, CA: Jossey-Bass, 2002.

26. Henry, J. An Ethnography of Change: Teacher-Research as Dissertation. In: R. Hubbard and B. Power (Eds.), Living the questions: A Guide for Teacher-Researchers, Portland, ME: Stenhouse, 196-204, 1999. 
27. Pearson, P. D., and Gallagher, M. C. The Instruction of Reading Comprehension. Contemporary Education Psychology 8: 317-344 (October 1983).

28. Hughes, L. "Thank You, M'am," 1958. http://www.americanliterature.com/Hughes/SS/ThankYouMam.html.

29. Fitzgerald, F. S. The Great Gatsby, New York: Simon \& Schuster, 1995.

30. Jenkins, H. Convergence Culture: Where Old and New Media Collide, New York: New York University Press, 2008.

\section{ABOUT THE AUTHOR}

Dr. Martin is a lecturer in Literacy at the University of Maine, College of Education and Human Development, and associate director of the Maine Writing Project. A former high school English teacher and K-12 technology integration coach, Dr. Martin's research interests include online discussion, preservice and in-service teachers' technology integration, and adolescent literacy. 